\title{
Simulation of Expansion Joint of Bottom Lining in Ladle and Its Influence on Thermal Stress
}

\author{
http://dx.doi.org/10.3991/ijoe.v9i2.2557 \\ Gongfa Li, Jia Liu, Guozhang Jiang, Jianyi Kong, Liangxi Xie ,Zheng Li \\ Wuhan University of Science and Technology, China
}

\begin{abstract}
Ladle is an important equipment of the metallurgical industry. Distribution of thermal stress in bottom linings has an essential influence on its life, and the size of its life-span affects the economic benefits of the iron and steel enterprise directly. In the process of design and calibration of the large-size ladle, it is of great significance to determine the stress distribution of each part of the ladle for safely and reliably running the device. Expansion joint has an important effect on the thermal stress of ladle composite construction body. The thermal expansion stress is one of important reasons that lead to damage, so it is of great practical value to calculate the thermal expansion stress. Expansion joint question between the inside linings could be summed up as a kind of contact question, whose physical model was set up, and the finite element model of expansion joint of bottom lining in ladle was built. The contact stress of expansion joint in each layer was researched. The results illustrate that setting 2 millimeters expansion joint can reduce the contact stress which is equate to $1 / 6 \sim 1 / 5$ of crushing strength of the lining.
\end{abstract}

Index Terms-Ladle, Thermal stress, Expansion joint, Bottom lining, Finite element method.

\section{INTRODUCTION}

The thermal stress is one of important facors which lead to the ladle damage as ladles operate under conditions of high temperature and overload. The thermal expansion arises in the ladle lining and shell which are associated with high temperature. When the deformation arising from the thermal expansion in the ladle lining and shell is subjected to mutual constraint each other, the thermal expansion stress was generated. The most effective approach of adjusting the ladle thermal expansion stress is to set up the expansion joint. Whereas, if the expansion joint is too large, it easily results in "molten steel seepage" and causes serious accidents; if the expansion joint is too little, the thermal stress expands, which diminishes the service life of the shell and refractory bricks. Therefore, calculation of the thermal expansion stress is of great practical value.

The lining expansion joint value is defined during the ladle construction. Flanks on the ladle lining bricks requiring the expansion joint are added up with normal thickness papers. The papers combust as a result of high temperature when the ladle enters the working condition of subjected molten steel at the end of heating the ladle. And then the expansion joint appears in the paper location. The expansion joint value of the ladle lining determined, the thermal stress of the ladle lining decreases. At the same time, the accident of steel seepage of the ladle is avoided occurring. So the expansion joint left in the lining expansion joint is just filled with expanded lining bricks in order to guarantee production safe when the ladle is transferred into the working condition of subjected molten steel after heating the ladle.

The approach that the thermal stress in the ladle with the expansion joint was defined by the finite element method was: choosing the thermal-structural coupled element could obtain both the temperature field and thermal stress as well as the normal pressure not only between lining bricks but also on the contact surface between lining bricks and the shell.

\section{PHYSICAL MODEL OF CONTACT PROBLEMS}

The contact problem is one type of complex nonlinear problems, which belongs to nonlinear problems of the boundary condition. The complexity mainly derived from change of system states, seperate and contact between objects namely. In contact problems, the contact surface between two contacts is commonly unknown beforehand, and the boundary condition is not prescribed before calculation but is given by the computation result. Area and pressure distributions of the contact surface between two contacts depend on change of the applied load and initial gap and are related to the contact stiffness. There are primarily the penalty method and penalty method combined with Lagrange multiplier method for dealing with contact problems. When gap between the contact and target surface is greater than zero, the contact status is closed; otherwise it switches to open. The contact penetration is denoted by the gap value. As the contact node penetrates the target surface, the contact occurs. The relation between normal force $F n$ which the contact section is subjected to and gap value is represented as[5]:

As for the penalty method, the normal contact force is denoted by ${ }^{[5]}$ :

$$
\mathrm{F}_{\mathrm{n}}= \begin{cases}\mathrm{K}_{\mathrm{n}} \times \mathrm{g} & \mathrm{g} \leq 0 \\ 0 & \mathrm{~g} \geq 0\end{cases}
$$

Where $K_{n}$ is contact stiffness; $\mathrm{g}$ is contact gap.

For the penalty method combined with Lagrange multiplier method, Lagrange polynomial of force is iterated repeatedly in each element. The normal contact force is indicated as:

$$
F_{n}=\min \left(0, \mathrm{~F}_{\mathrm{n}} \times \mathrm{g}+\lambda_{\mathrm{i}+1}\right)
$$

Where $\lambda_{i}$ is Lagrange multiplier force in the $i+1$ iteration, which is represented by: 


$$
\lambda_{1+1}= \begin{cases}\lambda_{\mathrm{i}}+\mathrm{a} \times \mathrm{K}_{\mathrm{n}} \times \mathrm{g} & |\mathrm{g}| \geq \mathrm{FTOLN} \\ \lambda_{\mathrm{i}} & |\mathrm{g}| \leq \mathrm{FTOLN}\end{cases}
$$

Where FTOLN is allowable penetration tolerance defined by users. $a$ is inner calculation factor $(a<1)$.

The friction force on the contact surface, the tangential force of the contact surface namely, is introduced owing to increasing frictions which contact nodes coming together and moving towards target nodes result in.

For three types of friction forms (free friction, elastic Coulomb friction and rigid Coulomb friction), note that the friction force is given by:

$$
\mathrm{F}_{\mathrm{s}}=\left\{\begin{array}{c}
0 \\
F_{t} \times \mathrm{u}_{\mathrm{s}}^{\mathrm{e}}<\mu \times \mathrm{F}_{\mathrm{s}}^{1} \\
\mathrm{~F}_{\mathrm{s}}^{1}
\end{array}\right.
$$

Where $\mathrm{Ft}$ is adhesive stiffness. $\mathrm{u}_{\mathrm{s}}^{\mathrm{e}}$ is elastic tangential deform. $\mu$ is the adhesive force limit in the Coulomb friction mode. $\mathrm{F}_{\mathrm{s}}^{1}$ is ratio of coefficient of static-dynamic friction.

\section{FINITE ELEMENT MODEL OF EXPANSION JOINT OF THE LADLE BOTTOM LINING}

The expansion joint of the ladle bottom lining is similar to the expansion joint of the ladle wall lining in the treatment method, except being set along the direction of the ladle height. Finite element models of the working layer and permanent layer as well as the permanent layer and outer shell were shown as Fig.1 2. Where $\mathrm{a}=$ $120 \mathrm{~mm}, \mathrm{~b} 3=4.5 \mathrm{~mm}, \mathrm{~b} 4=1 \mathrm{~mm}, \mathrm{~h} 1=230 \mathrm{~mm}, \mathrm{~h} 2=$ $162 \mathrm{~mm}, \mathrm{~h} 3=75 \mathrm{~mm}$.

\section{NUMERICAL SIMULATION OF CONTACT STRESS IN EXPANSION JOINT OF EACH LAYER}

\section{A. Contact stress between the working layer and the permanent layer}

Fig.3 gave the contour of temperature field distribution in the working layer and permanent layer. The temperature distributed between $253 \sim 1560^{\circ} \mathrm{C}$. Fig. 4 illustrated the plot of contact stress varying with expansion joint change. From Fig.4, note that the contact stress generated on the contact surface by setting $2 \mathrm{~mm}$ expansion joint was $12.2 \mathrm{MPa}$; the contact stress introduced on the contact surface without the expansion joint was $21.5 \mathrm{MPa}$. It was seen that the contact stress on the contact surface declined gradually, which decreased $9.3 \mathrm{MPa}$ at most as the expansion joint increased.

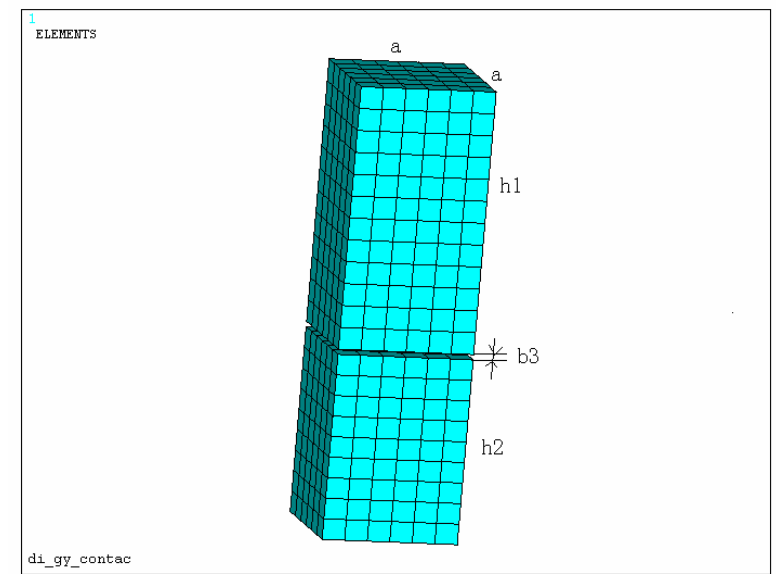

Figure 1. Finite element model of the working layer and permanent layer

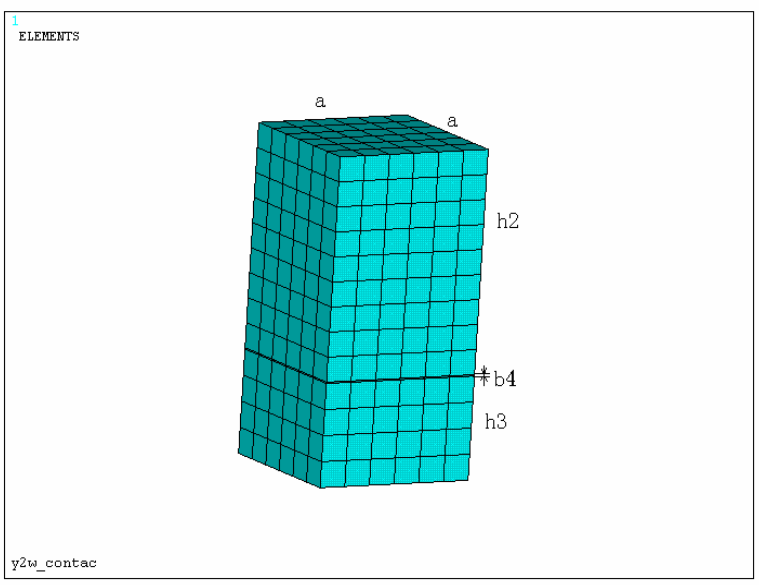

Figure 2. Finite element model of the permanent layer and shell

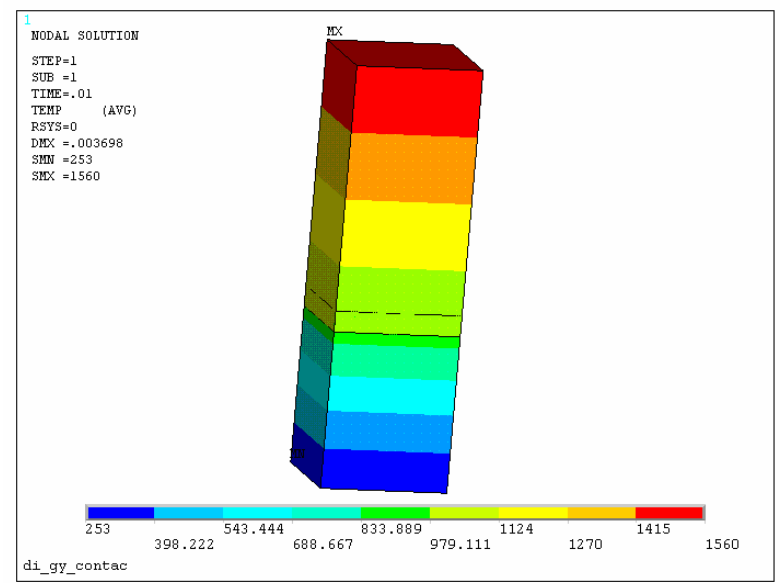

Figure 3. Contour of temperature field distribution in the working layer and permanent layer 


\section{B. Contact stress between the permanent layer and shell}

Fig.5 illustrated the contour of temperature field distribution of the permanent layer and shell and the temperature was between $249 \sim 988^{\circ} \mathrm{C}$. Fig. 6 exhibited the plot of contact stress varying with expansion joint change. From Fig.6, note that the contact stress which was induced on the contact surface of the refractory lining of the permanent layer when $1 \mathrm{~mm}$ expansion joint was set was $3.3 \mathrm{MPa}$ and the contact stress on the contact surface of the shell was $13.5 \mathrm{MPa}$; whereas, the contact stress which was generated on the contact surface of the refractory lining of the permanent layer when no expansion joint was set was $17.5 \mathrm{MPa}$ and the contact stress on the contact surface of the shell was $75.7 \mathrm{MPa}$.

Crushing strengths of the magnesia-carbon brick, alumina-magnesia-carbon brick, high alumina brick were $48 \mathrm{MPa}, 56.2 \mathrm{MPa}$, and $50.1 \mathrm{MPa}$, respectively. From the calculation above, note that the maximum contact stress on the contact surface $12.2 \mathrm{MPa}$ when $2 \mathrm{~mm}$ expansion joint was set between the working layer and the permanent layer; nevertheless, the maximum contact stress on the contact surface increased by about $10 \mathrm{MPa}$ and its increment occupied $1 / 6 \sim 1 / 5$ of crushing strength of the refractory material. It was of extreme disbenefit to the service life of refractory bricks.

\section{CONCLUSION}

It was obtained through simulation of effect of axial expansion joint of the ladle bottom on the ladle stress field that the difference of the contact stress between unsetting expansion joint and setting $2 \mathrm{~mm}$ expansion joint took up $1 / 6 \sim 1 / 5$ of crushing strength of the refractory material. It was extraordinarily detrimental to the service life of refractory bricks. The effect of the lining expansion joint on the ladle stress field could not be negligible.

\section{ACKNOWLEDGEMENT}

This research reported in the paper is supported by The Hubei Province Key Laboratory of Refractories and Ceramics Ministry-Province jointly-Constructed Cultivation Base for State key Laboratory (G201007), Natural Science Foundation of Hubei Province of China(2010CDA023) and National Natural Science Foundation of China(51075310). This support is greatly acknowledged.

\section{REFERRENCE}

[1] Guozhang Jiang, Jianyi Kong and Gongfa Li. Research on Temperature Distribution Model of Ladle and Its Test[J]. CHINA METALLURGY, 2006, 16 (11): 30-32

[2] Guozhang Jiang, Shijie Chen and Jianyi Kong. Simulation and Analysis of Stress Field of Ladle Wall Under a Subjected Molten Steel Shell[J]. METALLURGICAL EQUIPMENT, 2006, (5):1012

[3] Guozhang Jiang, Jianyi, Kong Yourong Li. Calculation of temperature distribution of ladle lining[A]. The Chinese Ceramic Society. The proceeding of the fourth international symposium on refractories[C], Beijing: International Academic Publishers/Beijing World Publishing Corporation, 2003: 289-292.

[4] Guozhang Jiang, Jianyi Kong and Gongfa Li. Influence of Expansion Joint of Ladle Lining on Thermal Stress[J]. CHINA METALLURGY, 2007, 17(12): 25-27

[5] Zhiqiang Guo, Xueping Ren. Effect of Lining Expansion Joint on Contact Pressure Between Lining and Shell[J]. IRON STEEL VANADIUM TITANIUM, 2003, 24(3): 42-45

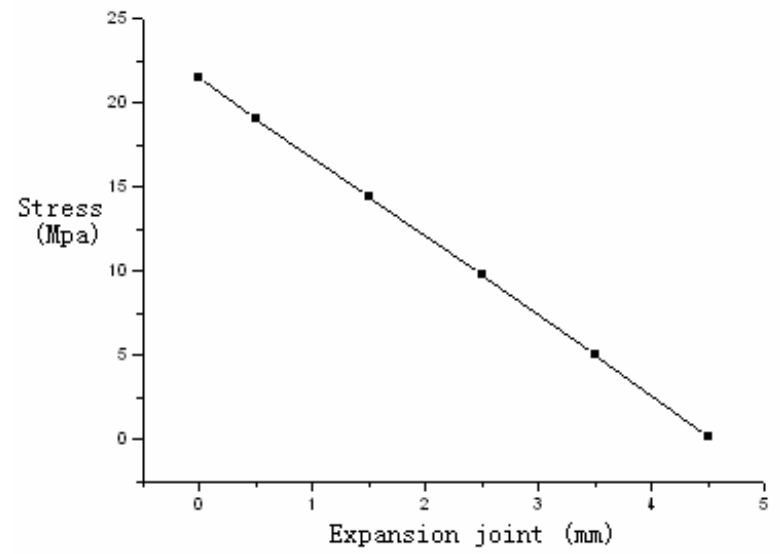

Figure 4. Plot of contact stress between working layer and permanent layer varying with expansion joint change

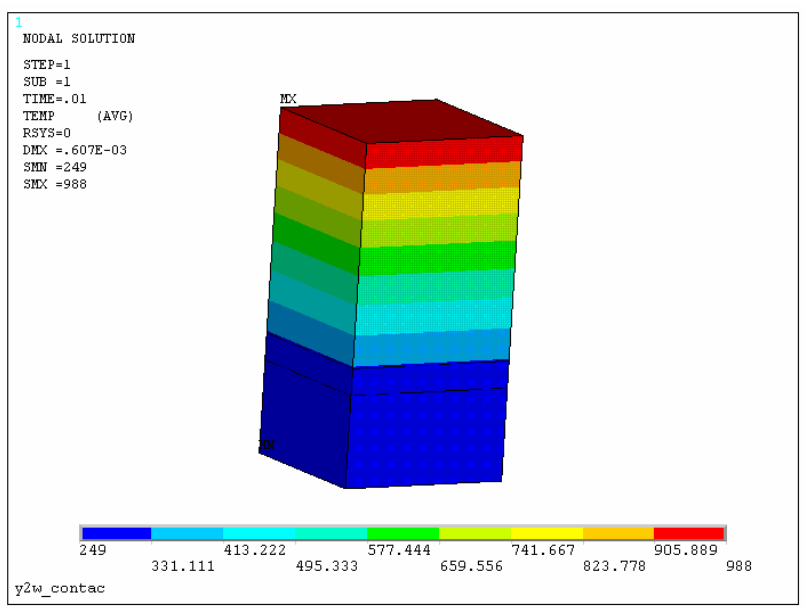

Figure 5. Contour of temperature field distribution of the permanent layer and shell

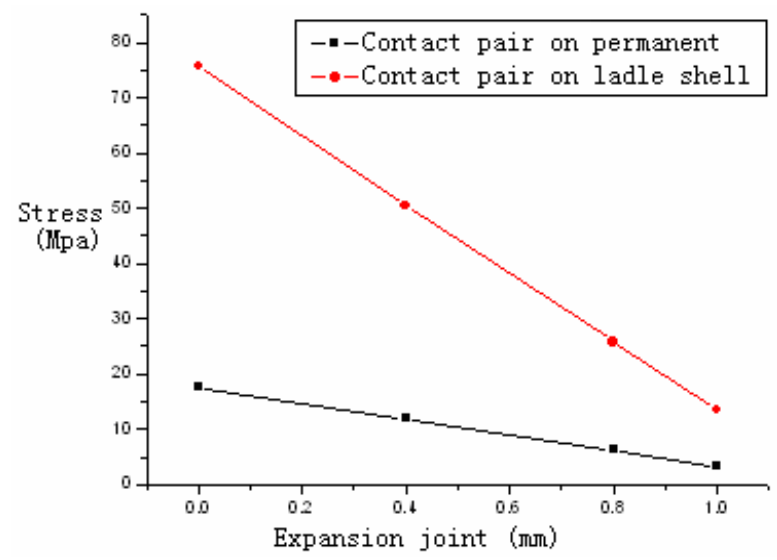

Figure 6. Contour of contact stress between permanent layer and shell varying with expansion joint change

[6] Dihua Qiu. Mechanics of Materials[M]. Bejing: Higher Education Press, 2004

[7] Shijie Chen, Guozhang Jiang, Jianyi Kong. Optimizing the structure of ladle bottom based on finite element method[C]. Proceedings of the International Workshop on Modern Science and Technology in 2006, 2006: 492 495.

[8] Shijie Chen. Research on Thermomechanical stress in Ladle Composite Construction Body and its service life prediction [D]. Wuhan: College of Machinery and Automation in Wuhan University of Science and Technology, 2007 


\section{AUTHORS}

Dr. Gongfa Li received the Ph.D. degree in mechanical design and theory from Wuhan University of Science and Technology in China. Currently, he is an associate professor at Wuhan University of Science and Technology, City College and College of Machinery and Automation, China. His major research interests include modeling and optimal control of complex industrial process. He is invited as a reviewer by the editors of some international journals, such as Environmental Engineering and Management Journal, International Journal of Engineering and Technology, International Journal of Physical Sciences, International Journal of Water Resources and Environmental Engineering, etc. He has published nearly ten papers in related journals.

Jia Liu was born in Shanxi province, P. R. China, in 1990. He received B.S. degree in mechanical engineering and automation from Wuchang institute of Technology, Wuhan, China, in 2012. He is currently occupied in his M.S. degree in mechanical design and theory at Wuhan University of Science and Technology, College of Machinery and Automation. His current research interests include mechanical CAD/CAE, signal analysis and processing.

Guozhang Jiang was born in Hubei province, P. R. China, in 1965. He received the B.S. degree in Chang'an University, China, in 1986, and M.S. degree in Wuhan University of Technology, China, in 1992. He received the Ph.D. degree in mechanical design and theory from Wuhan University of Science and Technology, College of Machinery and Automation, China, in 2007. He is a Professor of Industrial Engineering, and the Assistant Dean of the college of machinery and automation, Wuhan University of Science and Technology. Currently, his research interests are computer aided engineering, mechanical $\mathrm{CAD} / \mathrm{CAE}$ and industrial engineering and management system.

Jianyi Kong received the Ph.D. degree in mechanical design from Universität der Bundeswehr Hamburg, Germany, in 1995. He was awarded as a professor of Wuhan University of Science and Technology in 1998. Currently, he is the president of Wuhan University of Science and Technology, China. He services on the editorial boards of the Chinese journal of equipment manufacturing technology. He is a director of the Chinese society for metals, etc. His research interests focus on intelligent machine and controlled mechanism, dynamic design and fault diagnosis in electromechanical systems, mechanical CAD/CAE, intelligent design and control, etc.

Liangxi Xie is an associate professor in Wuhan University of Science and Technology, College of Machinery and Automation, China. He major in mechanical design and theory and focus on the research of rotorary vane steering gear (RVSG) and vane seals. He has published more than ten papers in related journals.

Zheng Li was born in Hubei province, P. R. China, in 1989. He received B.S. degree in mechanical engineering and automation from Wuhan University of Science and Technology, Wuhan, China, in 2012. He is currently occupied in his M.S. degree in mechanical design and theory at Wuhan University of Science and Technology, College of Machinery and Automation. His current research interests include mechanical $\mathrm{CAD} / \mathrm{CAE}$, signal analysis and processing.

This article is an extended and modified version of a paper presented at the International Conference on Mechanical Engineering, Automation and Material Science (MEAMS2012), held 22-23 December 2012, Wuhan, China. Received 16 March 2013. Published as resubmitted by the authors 25 March 2013. 